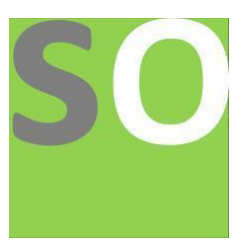

Article title: Determining Wind Actions in Kenya according to the Eurocodes

Authors: Muthomi Munyua[1]

Affiliations: University of Nairobi[1]

Orcid ids: 0000-0002-5786-4032[1]

Contact e-mail: muthomimunyua@gmail.com

License information: This work has been published open access under Creative Commons Attribution License $\mathrm{http}: / / c r e a t i v e c o m m o n s . o r g / l i c e n s e s / b y / 4.0 /$, which permits unrestricted use, distribution, and reproduction in any medium, provided the original work is properly cited. Conditions, terms of use and publishing policy can be found at https://www.scienceopen.com/.

Preprint statement: This article is a preprint and has not been peer-reviewed, under consideration and submitted to ScienceOpen Preprints for open peer review.

Funder: Self

DOI: 10.14293/S2199-1006.1.SOR-.PPBRJ1U.v1

Preprint first posted online: 22 June 2020

Keywords: Eurocodes, Wind, Kenya, Economic, Design, Gusts, CP3 


\title{
Determining Wind Actions in Kenya according to the Eurocodes
}

\author{
Muthomi Munyua \\ School of Engineering, University of Nairobi \\ P.O. Box 30197 - 00100, Nairobi \\ Email:muthomi@uonbi.ac.ke
}

\begin{abstract}
This paper provides guidance on using existing national parameters with the Eurocodes for determination of wind loads on buildings. The current code of practice allows engineers to use 3-second gusts which end up making the structures unnecessarily robust and uneconomical. This paper argues the case for using sustained wind speeds in the Eurocodes as opposed to wind gusts. The use of sustained wind speeds allows a $30 \%$ reduction on the magnitude of wind actions applied to a structure during design and consequently, a reduction in construction costs. Next, this paper demonstrates the method in which the current wind speeds given in 3-second gusts are converted to 10-minute wind speeds. The use of sustained wind speeds allows the engineer to come up with economical designs, thus improving the economic viability of construction projects. This paper provides guidance to applying wind actions on structures according to the Eurocode standard KS EN 1991-1-4.
\end{abstract}

Keywords: Eurocodes, Wind, Kenya, Economic Design, Gusts, CP3

\section{Introduction}

\subsection{Background}

Wind actions are one of the loads that are of great significance in determining the stability of structures. There are two main methods of quantifying wind speeds:

1. Sustained wind speeds

2. Wind Gusts

Sustained winds speeds are the steady or average wind speeds over a duration of time usually over a 10-minute duration (US: 1-minute) while wind gusts are sudden increases in wind speeds that are transient and last for less than 20 seconds [1]. Wind gusts are usually about $30 \%$ stronger than sustained wind speeds [2]. Wind gusts are quite variable and depend on different dynamics, such as location and terrain. Sustained wind speeds give us a more accurate idea of how steady the wind speed is.

\subsection{Problem Statement}

Developers avoid the services of engineers mainly because of the following reasons related to cost:

1. Engineering services are perceived to be expensive in comparison to services offered by experienced technicians.

2. Engineering specifications are deemed to be unnecessarily conservative, resulting in additional expenses.

This paper focuses on the magnitude of wind actions/loads applied to structures in Kenya in line with the local regulations. The magnitude of the loads at the design stage contribute significantly to the cost of the construction project. The current practice in Kenya is to use the 3-second wind gusts, which are higher than the sustained wind speeds, thus resulting in expensive designs. Kenya adopted the Eurocode Standards on $14^{\text {th }}$ September 2012 via Gazette Notice No. 13048 [3]. The Eurocodes specifies that 10-minute wind speed is to be used [4]. Wind data provided by the standardisation body, KEBS, and the weather monitoring service, KMD are in 3-second gusts.

The main problem is inadequate guidance on how to convert a 3 -second gust to 10 -minute wind speeds.

\subsection{Objective}

1. To provide guidance on how to apply wind actions on structures in Kenya when designing in accordance with the Eurocodes.

2. To improve the cost-effectiveness of structural designs.

\subsection{Justification of the Study}

The Eurocodes were adopted in Kenya without the relevant National Annexes. This paper guides on how to use the new codes with the existing data as the National Annexes are being developed. It will guide how to modify existing wind speeds provided by both KEBS and KMD, to the Eurocodes.

\subsection{Scope}

This study is limited to using existing data published in 1977 by KEBS [5]. Due to the effects of climate change and other human activity such as deforestation, there is a high likelihood that these design data may be outdated. Nonetheless, these data are still in use in Kenya.

\section{Materials and Methods}

\subsection{Current Practice}

The current practice in Kenya is based on previous UK practice, that is $\mathrm{CP} 3$ [6]. Ideally, the $\mathrm{CP} 3$ should only be used in the UK, but its application found its way to Kenya. Engineers ignore the UK wind map in CP3 and instead use Table 1 of the Kenya Standard KSO2- 
26:1977 [5] reproduced in this paper as Table 1. This table is used when determining wind speed at a site.

\begin{tabular}{|l|c|}
\hline Location & $\begin{array}{l}\text { Basic Wind } \\
\text { Speed (m/s) }\end{array}$ \\
\hline Coast province, Voi, Garissa & 31 \\
\hline Nairobi, Machakos, Kitui, Isiolo & 27 \\
\hline $\begin{array}{l}\text { Nakuru, Naivasha, Magadi, } \\
\text { Nanyuki, Rumuruti }\end{array}$ & 36 \\
\hline $\begin{array}{l}\text { Eldoret, Kitale, Narok, Magadi, } \\
\text { Rift Valley Province, Kisumu, } \\
\text { Nyanza Province, Western Province }\end{array}$ & 45 \\
\hline Table 1: Horizontal wind speeds at 10m above the surface [5].
\end{tabular}

Table 1 has a few errors present:

1. Magadi town is presented on two rows with a wind speed of $36 \mathrm{~m} / \mathrm{s}$ and $45 \mathrm{~m} / \mathrm{s}$.

2. Data from Central Kenya is not presented.

3. All the towns in the third row are located in Rift Valley province. The fourth row shows data for Rift Valley province.

Because of these errors, there exists a table used by some consulting engineers that has corrected some of these errors. These values have not been published officially by any authority [7].

\begin{tabular}{|l|c|}
\hline Region & $\begin{array}{l}\text { Basic Wind } \\
\text { Speed (m/s) }\end{array}$ \\
\hline $\begin{array}{l}\text { Nairobi, Central and Southern Half } \\
\text { of Eastern Province }\end{array}$ & 28 \\
\hline $\begin{array}{l}\text { Northern Half of Eastern and North } \\
\text { Eastern Province }\end{array}$ & 40 \\
\hline Coast Province & 31 \\
\hline Southern Part of Rift Valley & 36 \\
\hline Nyanza and Western Province & 46 \\
\hline Table 2: The corrected version of KS02-26:1977 Table 1. \\
\hline
\end{tabular}

Despite the attempt to correct the errors present in Table 1, Table 2 omits data for the Northern part of Rift Valley. The wind speeds in Table 2 are also based on a 3 -second gust. Once the designer decides the wind speed to use at a site, the procedure in the CP3 is then followed. There has not been guidance on how to use the updated BS codes since the UK declared CP3 obsolete in 1998 [8], withdrew BS 6399-2 in March 2010 and adopted the Eurocodes. Engineers in Kenya continue to use data which was only fit for the obsolete CP3 [9].

It is also worth noting that the KMD released wind speeds that slightly differ with the information published by KEBS [5]. These wind speeds are also 3second gusts.

\begin{tabular}{|l|l|l|l|}
\hline Town/Return & \multicolumn{3}{|l|}{ Wind speed (m/s) } \\
\cline { 2 - 4 } period in years & $\mathbf{2 5}$ & $\mathbf{5 0}$ & $\mathbf{1 0 0}$ \\
\hline Mombasa & 25.9 & 28.1 & 30.3 \\
\hline Kisumu & 41.2 & 44.6 & 48.1 \\
\hline Nakuru & 29.0 & 31.3 & 33.9 \\
\hline
\end{tabular}

\begin{tabular}{|l|l|l|l|}
\hline Town/Return & \multicolumn{3}{|l|}{ Wind speed (m/s) } \\
\cline { 2 - 4 } period in years & $\mathbf{2 5}$ & $\mathbf{5 0}$ & $\mathbf{1 0 0}$ \\
\hline Nanyuki & 33.1 & 35.9 & 38.7 \\
\hline Nairobi & 24.8 & 26.9 & 29.0 \\
\hline Kericho & 28.6 & 30.9 & 33.4 \\
\hline
\end{tabular}

A 50-year return period is typically used for designing buildings [7]. Thus, there is a 0.02 probability of exceedance, equivalent to a 50 year mean recurrence interval [11].

Decision after CP3 was declared obsolete by BSI The design process of using the design speeds from Kenya standard and $\mathrm{CP} 3$ has not been updated. However, after CP3 was declared obsolete and over time, some of Kenya's engineers opted to use BS 63992 with the same gust duration. Whereas this is indeed safer, it results in conservative designs that increase costs and leads to developers avoiding engineering services altogether.

\section{The difference in Design Codes used in Kenya}

The CP3 [9] uses a 3 -second gust, $V_{3}$, while the BS 6399-2 [12] utilises mean hour speed, $V_{3600}$. The Eurocodes use a 10-minute gust, $V_{600}[4]$. The nomenclature for the various wind speed duration is that proposed by the WMO. The nomenclature follows that an estimate of the true mean wind $V$ should be explicitly identified by its averaging period $T_{0}$ in seconds, described as $V_{T_{0}}$ [8].

Table 4 illustrates this:

\begin{tabular}{|l|l|c|}
\hline Code & Gust Period & Abbreviation \\
\hline CP3 & 3 seconds & $V_{3}$ \\
\hline BS 6399-2 & 1 hour & $V_{3600}$ \\
\hline EN 1991-1-4 & 10 minutes & $V_{600}$ \\
\hline \multicolumn{2}{|l|}{ Table 4: Wind Design codes and the respective gust periods. }
\end{tabular}

\subsection{Eurocode Adoption in Kenya}

The Eurocodes have nationally determined parameters that every country should provide to use the codes effectively. Unfortunately, Kenya has not yet developed such. Engineers continue to use the Kenya Standard KS02-26:1977 Table 1 [5] when determining wind speeds at a site.

The KS wind speeds utilise 3-second wind gusts. This gust period is used because of the response time of mechanical anemometers. The response time is usually 1-3 seconds and is a function of the inertia of the system [8]. This response time is the main reason that several other countries, such as the UK, US and Australia, used the 3-second gust duration [8].

The Eurocode utilises a 10-minute gust [4]. A 10minute gust is likely to be of lower speed than a 3second because, over a shorter period, mean velocities 
are higher since there is less chance to cancel out a peak in the duration of the recording.

\subsection{UK National Annexes}

The Government of Kenya declared the Eurocodes as its national standards [3] even though the standardisation body, KEBS, had not developed the relevant annexes. An article in The Kenya Engineer, the journal of the Institution of Engineers of Kenya, states that the UK National Annexes were to be used [13]. The article implicitly describes the UK National Annex as one single document. That implication is not accurate. There are several annexes to be used with the Eurocodes. Each specific part of the Eurocode is accompanied by its relevant annex.

Another problem is that the UK NA is not applicable in localised scenarios such as that of wind or snow. Kenya and the UK have different climates. The local conditions of the two are quite different. The wind speed in the UK is usually read directly from a wind map in the UK NA [14]. Then, using the formula EC1-1-4 Eqn (4.10), reproduced as Expression (1), the basic velocity pressure, $q_{b}$ is calculated as:

$$
\text { basic velocity pressure, } \quad q_{b}=\frac{\rho v_{b}{ }^{2}}{2}
$$

After that, the basic velocity pressure is multiplied by an exposure factor $c_{e}(z)$ as given by the formula EC11-4 Eqn (4.8). However, that expression is overridden by Eqn (NA.3a), reproduced as Expression (2), to get the peak velocity pressure. This peak velocity pressure is then applied to the structure:

$$
\text { peak velocity pressure, } \quad q_{p}=c_{e}(z) \times q_{b}
$$

$c_{e}(z)$ is specific to the UK and is a function of the distance to the sea.

\section{Challenges of using the UK NA in Kenya}

1. The UK NA is based on the fact that the UK is generally at a low-lying level with an average altitude of approximately $162 \mathrm{~m}$ above sea level. Kenya has an average altitude of $762 \mathrm{~m}$ above sea level [15]. Several areas in Kenya are also highlands with a mean sea level of $1500 \mathrm{~m}$ above sea level.

2. The UK wind map is based on a reference datum hence the need for an altitude correction factor $c_{\text {alt }}$ whereas the KS02-26:1977 Table 1 gives speed at $10 \mathrm{~m}$ above the ground at a particular location.

3. The UK is an island and experiences a marine climate throughout the entire country. The distance to the sea is therefore essential when determining the wind speed at a site. In contrast, Kenya is continental with significant geographical formations that influence the wind pattern, and the climate is not directly affected by the distance to the sea.

4. The UK, as stated in Clause NA 2.18, uses an air density value of $1.226 \mathrm{~kg} / \mathrm{m}^{3}[14]$ whereas this study found no value for the density of air in Kenya. EC1$1-4$ recommends a value of $1.25 \mathrm{~kg} / \mathrm{m}^{3}$. This value is more onerous than that of the UK [4].

\section{Other Eurocode Challenges}

Kenya adopted all the Eurocodes, including the Snow Eurocode. Kenya is at the equator and experiences a tropical climate. Kenya hardly experiences any snowfall except at the peaks of Mt. Kenya, with an altitude of approximately 5,200 metres above sea level. This fact does not mean that KEBS erred in its adoption of the Snow Eurocode KS EN 1991-1-3 [16]. Some parts of Kenya receive significant hail which takes days to thaw [17]. Kericho, Laikipia, Nakuru, and Nyandarua counties have records of experiencing significant hail. Hail is covered in the Snow Eurocode EC1-1-3.

\subsection{Wind map}

This paper only focused on existing data and existing design procedures. Further research will be necessary to incorporate the 40 years of weather data in creating Kenya's wind map.

The data given in KS02-26:1977 showed points and areas with the same wind speed. A map of these wind speeds was modelled, and isotachs were drawn. Isotachs are lines on a map with equal wind speeds [18]. The jurisdiction of the map is as per the Constitution of Kenya, 2010 [19].

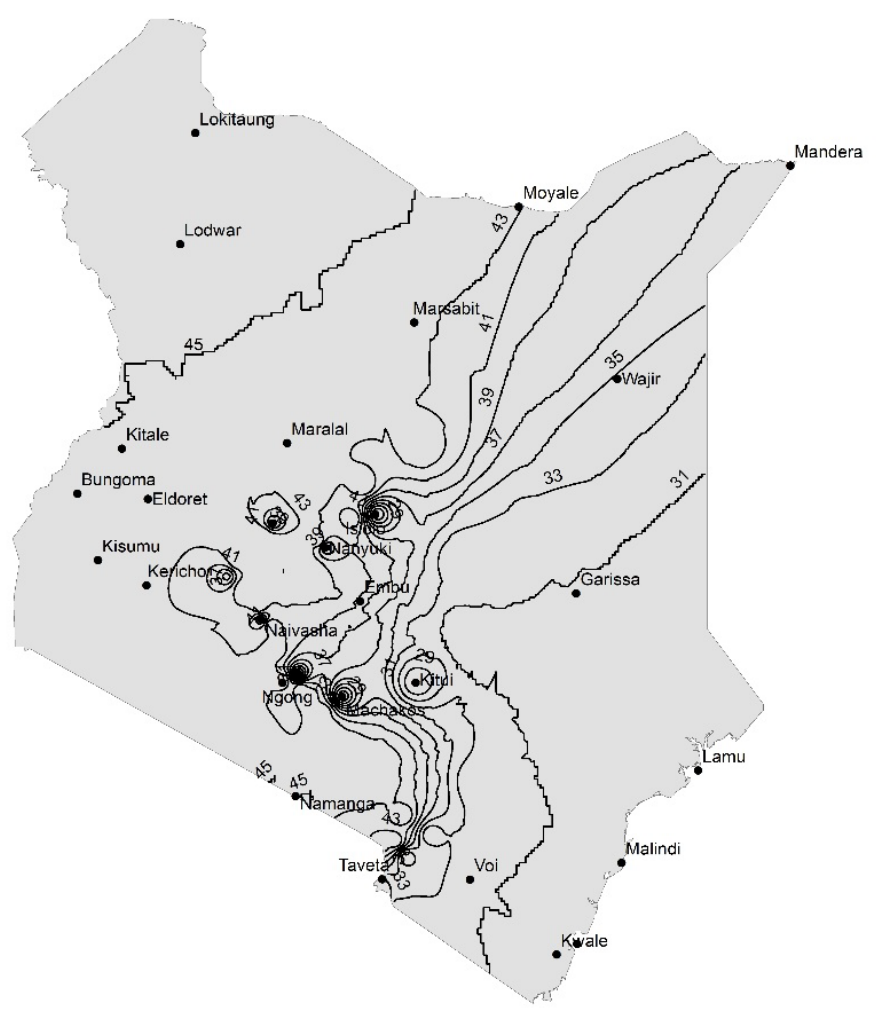

Figure 1: Isotachs generated from Table 1 of KS02-26:1977. 
It is essential to review these wind speeds. KMD has been collecting data on wind speed over the years, and it is vital to consider the new data and incorporate this information in how engineers in Kenya design structures safely and economically.

Based on statistics, the shorter the wind gust period, the higher the velocity. This fact does not imply less safety since a collapse due to wind will most likely occur because of a sustained wind speed of over 10 minutes and not a wind gust. The wind gust duration is the main difference between the two codes. A Durst curve was employed to convert the 3-second gust to the 10-minute wind speed.

A Durst curve is a statistical correlation between wind speeds over different wind speed durations.

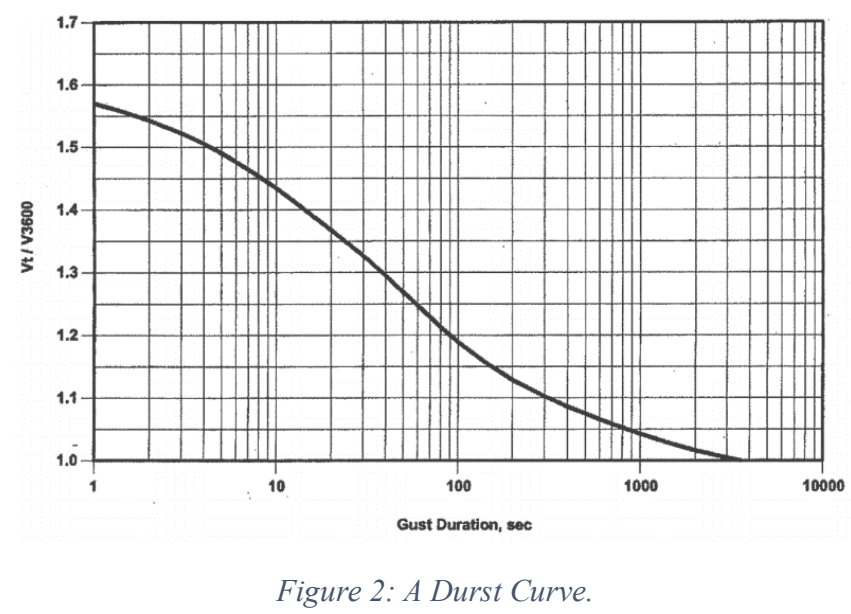

\section{Discussion}

\subsection{Interpretation}

Kenya's method of determination of wind actions on structures will deviate from the method presented in the UK NA. The wind duration must be converted from $V_{3}$ to $V_{600}$. The peak velocity pressure should be calculated using the formula in EC1-1-4 Eqn (4.8) [4]. The exposure factor $c_{e}(z)$ as proposed in the UK NA cannot apply locally as wind speed is not directly affected by distance to the sea in Kenya.

\subsection{Integration}

\section{Proposed Procedure}

To determine the wind actions on a structure in Kenya, an engineer may have to use a Durst Curve.

A Durst curve was used to convert the wind speeds given by Table 1 in the KS02-26 and that by KMD to 10-minute wind speeds as follows [20]:

$$
V_{600}=\frac{V_{3}}{1.52} \times 1.06
$$

The conversion using the Durst curve is usually replicated empirically where 10-minute wind speeds are
$6 \%$ higher than mean hourly speeds [11]. The Durst curve was used to determine the 10-minute wind speeds in the UK NA from the mean hourly wind speeds that were in BS 6399-2.

The values in Table 2 were converted to 10-minute wind speeds and presented in Table $\mathbf{5}$.

\begin{tabular}{|l|c|}
\hline Location & $\begin{array}{c}\text { Basic Wind Speed } \\
{\left[V_{600}\right] \mathbf{( m / s )}}\end{array}$ \\
\hline $\begin{array}{l}\text { Nairobi, Central and Southern } \\
\text { Half of Eastern Province }\end{array}$ & 19.5 \\
\hline $\begin{array}{l}\text { Northern Half of Eastern and } \\
\text { North Eastern Province }\end{array}$ & 27.9 \\
\hline Coast Province & 21.6 \\
\hline Southern Part of Rift Valley & 25.1 \\
\hline Nyanza and Western Province & 32.1 \\
\hline \multicolumn{2}{|c|}{ Table 5: Proposed wind speeds when using the Eurocode. } \\
\hline
\end{tabular}

It is challenging to generate isotachs with data from Table 5 because it specifies wind speed for large geographical areas and not single locations, like towns, as had been specified in Table 1.

Once the wind speed has been determined and the basic mean speed $V_{600}$ has been calculated, the engineer may then use the procedure determined by the Eurocode as adopted by KEBS in the standard KS EN 1991-1-4.

The basic velocity pressure can then be calculated using Eqn (4.10) of EC 1-4 with the recommended value of air density $\rho=1.25 \mathrm{~kg} / \mathrm{m}^{3}$. The peak velocity pressure should then be calculated using Eqn (4.8) and not Eqn (NA.3a).

$$
q_{p}(z)=\left[1+7 I_{v}(z)\right] \times \frac{1}{2} \rho v_{m}^{2}(z)
$$

The procedure in the UK NA can then be followed to determine the wind actions on the structure or parts of the structure.

\subsection{Implication}

The value for Nairobi wind speed of $19.5 \mathrm{~m} / \mathrm{s}$ in Table 5 is similar to that found out in a separate study where wind data from eight weather stations around Nairobi City County, Kenya, was collected and analysed [7]. That study showed that the wind speed $V_{600}$, in Nairobi City County varied from $18 \mathrm{~m} / \mathrm{s}$ to $22 \mathrm{~m} / \mathrm{s}$. Currently, most structural engineers in Nairobi use a wind speed of $28 \mathrm{~m} / \mathrm{s}$ when applying wind actions to structures [21]. Adopting a wind speed of $19.5 \mathrm{~m} / \mathrm{s}$ instead of $28 \mathrm{~m} / \mathrm{s}$ will result in a $30 \%$ reduction of the magnitude of wind actions. This reduction will result in cost savings of construction projects.

It is possible to use the Eurocodes in Kenya as KEBS develops the Kenya National Annexes. A combination of the local table values from Table 1 of KS02-26:1977 and the UK NA can be used to determine wind actions on structures when designing to the Eurocodes. 


\section{Conclusion}

The objectives of this study were achieved. The paper has demonstrated how to use existing wind data to determine wind actions on structures in Kenya when designing according to the Eurocodes. A 30\% reduction of wind loads was achieved by using a 10-minute wind speed as opposed to a 3-second gust. This reduction may lead to an increase in the economic viability of construction projects at the design stage.

\section{Recommendations}

1. Further research incorporating current data from KMD and other weather \& climate monitoring organisations should be conducted.

2. A design guide for the determination of wind actions on structures in Kenya.

3. A study to find out the density of air in Kenya should be done.

\section{References}

[1] American Meteorological Society, 'Glossary of Meteorology', Gust, Oct. 06, 2019. http://glossary.ametsoc.org/wiki/Gust.

[2] eMeteorology, Wind Gust and Sustained Wind What's the Difference? 2018.

[3] Republic of Kenya, 'Gazette Notice No. 13048', The Kenya Gazette, Nairobi, pp. 3417-3418, Sep. 14, 2014.

[4] CEN, 'EN 1991-1-4:2005+A1:2010 Eurocode 1: Actions on structures - Part 1-4: General actions Wind actions', European Committee for Standardization, 2010.

[5] KEBS, 'KS02-26-1977', Kenya Bureau of Standards, 1977.

[6] National Planning and Building Authority, Kenya, 'KS Code: 2009 - Building Code of the Republic of Kenya - Planning and Building Regulations', 2009.

[7] E. 0. Onkendu, 'Preparation of Nairobi County Wind Map as Part of the Kenya National Annex to EN 1991-1-4', Master's Thesis, Pan African University Institute for Basic Sciences, Technology and Innovation, Juja, Kenya, 2014.

[8] B. A. Harper, J. D. Kepert, and J. D. Ginger, 'Guidelines for converting between various wind averaging periods in tropical cyclone conditions.' World Meteorological Organization, Oct. 2008, Accessed: Oct. 06, 2019. [Online]. Available: https:/www.wmo.int/pages/prog/www/tcp/Meetin gs/HC31/documents/Doc.3.part2.pdf.

[9] BSI, 'CP3 Chapter V-2:1972 - Basic Data for the design of buildings - Chapter V: Loading - Part 2: Wind Loads', British Standards Institute, 1972.

[10]KMD, 'Kenya Wind Speeds'. Kenya Meteorological Department, 1977.

[11]A. F. Hughes, P394 - Wind Actions to BS EN 19911-4. Steel Construction Institute (SCI), 2014.

[12]BSI, 'BS 6399-2:1997 - Loading for Buildings Part 2: Code of practice for wind loads.', British Standards Institute, 1997.

[13]The Kenya Engineer, 'Eurocodes to Impact Engineering practice in Kenya', Aug. 09, 2016.

[14]BSI, 'NA to BS EN 1991-1-4:2005+A1:2010: UK National Annex to Eurocode 1 - Actions on structures - Part 1-4: General actions - Wind actions', British Standards Institute, 2011.

[15]Atlas Big, 'Average Elevation of Countries Interactive Map', https://www.atlasbig.com/en-us, Oct. 06, 2019.

[16]CEN, 'EN 1991-1-3: Eurocode 1: Actions on structures - Part 1-3: General actions - Snow', European Committee for Standardization, 2010.

[17]AfricaNews, 'Kenya enjoys rare snowy feel, but meteo agency says it was hail storm', Jul. 15, 2017. https://www.africanews.com/2017/07/05/kenyaenjoys-rare-snowy-feel-but-meteo-agency-says-itwas-hail-storm/ (accessed Oct. 07, 2019).

[18]'Definition of ISOTACH'. https://www.merriamwebster.com/dictionary/isotach (accessed Jun. 21, 2020).

[19]'The Constitution of the Republic of Kenya'. Government Printer, Aug. 2010.

[20]P. Dregger, 'The Wind Investigator: How to Approximate Wind Velocities at Roof Level', IIBEC Interface, pp. 41-43, Oct. 2005.

[21]E. 0. Ong'ayo, S. K. Mwea, and S. O. Abuodha, 'Determination of Basic Mean Hourly Wind Speeds for Structural Design in Nairobi County', Int. J. Eng. Sci. Emerg. Technol., vol. 7, no. 2, pp. 631-640, Oct. 2014.

\section{Abbreviations}

$\begin{array}{ll}\text { Acronym } & \text { Meaning } \\ \text { BS } & \text { British Standard } \\ \text { BSI } & \text { British Standards Institute } \\ \text { CEN } & \text { European Committee for Standardization } \\ \text { EC } & \text { Eurocode } \\ \text { EN } & \text { European Norm/ European Standard } \\ \text { KEBS } & \text { Kenya Bureau of Standards }\end{array}$

$\begin{array}{ll}\text { Acronym } & \text { Meaning } \\ \text { KMD } & \text { Kenya Meteorological Department } \\ \text { KS } & \text { Kenya Standard } \\ \text { NA } & \text { National Annex } \\ \text { UK } & \text { United Kingdom of Great Britain and } \\ & \text { Northern Ireland } \\ \text { WMO } & \text { World Meteorological Organization }\end{array}$

